\title{
The practice of poetry and the psychology of well-being
}

\author{
Adam M. Croom*
}

(Received 1 August 2014; accepted 22 September 2014)

In "Flourish," the psychologist Martin Seligman proposed that psychological well-being consists of AQ1 "PERMA: positive emotion, engagement, relationships, meaning, and accomplishment." Although the question of what constitutes flourishing or psychological well-being has been long debated among scholars, the recent literature has suggested that a paradigmatic or prototypical case of psychological well-being would manifest most or all of the aforementioned PERMA factors. The recent literature on poetry therapy has also suggested that poetry practice may be utilized as "an effective therapeutic tool" for patients suffering from a variety of ailments so it seems plausible that practicing poetry can $A Q 2$ positively contribute to one flourishing with greater psychological well-being. However, recent studies on poetry therapy have not yet been reviewed and integrated under the PERMA framework from positive psychology to further explore and explicate this possibility. This article therefore contributes to extant work by reviewing recent research on poetry therapy and psychological well-being and offering support for the claim that practicing poetry can positively contribute to one flourishing with greater psychological well-being by positively influencing their emotions, engagement or "flow" experiences, social relationships, sense of meaning or purpose in life, and personal accomplishments.

Keywords Poetry; therapy; positive psychology; flow; relationships; meaning

In "Flourish," the psychologist Martin Seligman (2010) proposed that psychological well-being consists of "PERMA: positive emotion, engagement, relationships, meaning, and accomplishment." Although the question of what constitutes flourishing or psychological well-being has been long debated among scholars, the recent literature has suggested that a paradigmatic or prototypical case of psychological well-being would manifest most or all of the aforementioned PERMA factors. The recent literature on poetry therapy has also suggested that poetry practice may be utilized as "an effective therapeutic tool" for patients suffering from a variety of ailments (cf. Kempler, 2003) so it seems plausible that practicing poetry can positively AQ4 contribute to one flourishing with greater psychological well-being. However, recent studies on poetry therapy have not yet been reviewed and integrated under the PERMA framework from positive psychology to further explore and explicate this

\footnotetext{
${ }^{\star}$ Corresponding author. Adam M. Croom, Department of Philosophy, University of Pennsylvania, AQ3 Philadelphia, PA 19104, USA. Tel: xxx. Email: croom@sas.upenn.edu
} 


\section{A. M. Croom}

possibility. This article therefore contributes to extant work by reviewing recent research on poetry therapy and psychological well-being and offering support for the claim that practicing poetry can positively contribute to one flourishing with greater psychological well-being by positively influencing their emotions, engagement or "flow" experiences, social relationships, sense of meaning or purpose in life, and personal accomplishments.

\section{Introduction}

In "Flourish: Positive Psychology and Positive Interventions," Martin Seligman (2010) raised the important point that although much effort in the psychological sciences has focused on developing interventions that are aimed at relieving misery, relatively little effort has likewise focused on developing interventions that are aimed at producing well-being (p. 233). Seligman (2010) accordingly argued for an approach to psychological research that he called positive psychology, which aimed at developing "interventions that build the enabling conditions of life, not just interventions that decrease misery," and further proposed that psychological well-being consisted of "PERMA: positive emotion, engagement, relationships, meaning, and accomplishment" (pp. 233-236; cf. Seligman, 2011, p. 24). Although the question of what constitutes psychological well-being or human flourishing has been long debated among scholars (cf. Aristotle, 2011; McMahon, 2006; Peterson \& Seligman, 2004), the recent literature has suggested that a paradigmatic or prototypical case of psychological well-being would manifest most or all of the aforementioned PERMA factors of positive emotion, engagement, relationships, meaning, and accomplishment (cf. Seligman, 2010, p. 236; 2011, p. 24). In "Music, Neuroscience, and the Psychology of Well-Being," for example, Croom (2012) applied the PERMA model to recent empirical evidence from the cognitive sciences to argue that regularly engaging in musical practice "could actually increase one's level of positive emotions, strong interpersonal relationships and rapport with others, commitment in engaging activities, level of accomplishment, and experience of meaning or purpose in life," and that consequently, there is "compelling evidence that musical engagement can positively contribute to one's living a flourishing life" (p. 11; cf. Croom, 2014). Rashid et al. (2014) similarly drew upon the conception of "Well-being and Resilience [...] as the integration of positive emotions, engagement, positive relationships, meaning and accomplishment (PERMA)" in their proposed strengthbased interventions for children and adolescents (pp. 162-165), and in "Well-Being and Resilience in School Settings," Noble and McGrath (2014) likewise proposed an approach to positive education that adopted the PERMA model to help students develop their "Social and emotional competencies," including "Positive emotions," "Positive relationships," "Positive purpose," and "Optimal learning environments that facilitate achievement" (p. 139; cf. Noble \& McGrath, 2008; Seligman, Ernst, AQ5 Gillham, Reivich, \& Linkins, 2009; Slavin, Schindler, Chibnall, Fendell, \& Shoss, 2012). This approach to investigating psychological well-being by investigating its common characteristics of positive emotions, engagement, social relationships, sense of meaning or purpose in life, and personal accomplishments, therefore, is a 
common and promising one to adopt for the purpose of investigating whether therapeutic practices involving poetry can contribute to one flourishing with greater psychological well-being.

Since the recent literature on the practice of poetry has suggested that poetry can be utilized as "an effective therapeutic tool" for patients suffering from a variety of ailments (Kempler, 2003, p. 217; cf. Ingram, 2003) it seems plausible that engaging $\mathrm{AQ}^{\mathrm{AQ}} 7$ in the practice of poetry can positively contribute to one flourishing with greater psychological well-being. Miller (1978) for instance investigated whether practicing poetry in a group setting could work as an effective form of treatment for patients ( $n$ $=8$ ) with psychosis and reported that "Discussing poems helped the patients identify with the artistic and creative aspects of their personalities, thus enhancing their ego function," and that "Encouraging expression through symbolization offered a safe outlet for discussing problems" (p. 138). In another study focusing on the use of poetry writing as a therapeutic aid for students pursuing doctoral study, Chan (2003) AQ8 also recently reported that poetry writing can help students relieve stress, promote self-understanding, and fill feelings of emptiness (p. 5). However, recent studies from the literature on poetry practice have not yet been reviewed and integrated under the PERMA framework from positive psychology to further explore and explicate the possibility that engaging in practices of poetry can positively contribute to one flourishing with greater psychological well-being. This article therefore contributes to extant work by reviewing the recent literature on poetry therapy and psychological well-being in order to offer evidential support for the claim that practicing poetry can positively contribute to one flourishing with greater psychological well-being by positively influencing their emotions, engagement or flow experiences, social relationships, sense of meaning or purpose in life, and personal accomplishments.

In order to appropriately begin the analysis of whether engaging in practices of poetry can positively contribute to one flourishing with greater psychological wellbeing, the next section (Section 2) will first review the recent literature on poetry and positive emotion to further clarify how practicing poetry can function as a useful means for positively influencing the emotions, and in so doing, positively influencing the first characteristic component of psychological well-being (the PERMA factor $\mathrm{P}$ for positive emotion).

\section{The practice of poetry for positive emotion}

Since psychological well-being is considered to consist of "PERMA: positive emotion, engagement, relationships, meaning, and accomplishment" (p. 236; cf. Seligman, 2011, p. 24) the first element to consider in our discussion of well-being is positive emotions $(\mathrm{P})$. Positive emotions have been considered by many to constitute an important element of psychological well-being, and several recent studies have offered insight on how positive emotions may contribute in this way. In "Building a Neuroscience of Pleasure and Well-Being," for example, Berridge and Kringelbach (2011) discussed how well-being has often been considered to involve "at least two crucial ingredients: positive affect or pleasure (hedonia) and a sense of 


\section{A. M. Croom}

meaningfulness or engagement in life (eudaimonia)" (p. 1) and proposed that "eudaimonic wellbeing" correlates with functional activity occurring in the anterior cingulate and in left prefrontal cortex whereas "hedonic wellbeing" correlates with functional activity occurring in the subgenual cingulate and orbitofrontal cortices (pp. 19-21). Berridge and Kringelbach (2011) further proposed that "happiness springs not from any single component but from the interplay of higher pleasures, positive appraisals of life meaning and social connectedness, all combined and merged by interaction between the brain's default networks and pleasure networks" (pp. 19-21). Similarly, Fredrickson (2006) reported that "pleasant affective states appear to be critical ingredients within the recipe for human flourishing" (p. 57) and Vallerand (2012) likewise argued that "Through the experience of positive emotions during activity engagement that takes place on a regular and repeated basis [...] harmonious passion contributes to sustained psychological well-being while preventing the experience of negative affect, psychological conflict, and ill-being" (p. 1; cf. Tang, Kelley, Hicks, \& Harmon-Jones, 2013). In other recent research, Robinson and Von Hippel (2006) investigated whether individual differences in life satisfaction are systematically related to memory networks favoring positive or negative affective priming in students $(n=198)$ and found that individuals low in life satisfaction displayed larger negative relative to positive affective priming effects whereas individuals high in life satisfaction displayed larger positive relative to negative affective priming effects, and concluded from this that "the memory organization of positive and negative thoughts influences life satisfaction" (pp. 194-195). More recently, Busseri, Choma, and Sadava (2012) investigated subjective evaluations of life satisfaction (LS), positive affect (PA), and negative affect (NA) in undergraduate students $(n=438)$ and reported finding that "higher levels of present SWB [subjective well-being] were aligned with greater positive psychological, physical, and interpersonal functioning" (p. 1). Thus collectively the results from these empirical and theoretical studies offer substantive support for the point that positive relationships constitute an important element to psychological well-being.

Importantly, since positive emotions can contribute to psychological well-being, practicing poetry can contribute to psychological well-being also insofar as practicing poetry can contribute to positive emotions. And several studies have indeed suggested that engaging with poetry can contribute to positive emotions. For example, Boone and Castillo (2008) found that poetry therapy reduced SPTSD AQ9 symptoms in domestic violence counselors (p. 3), Brillantes-Evangelista (2013) AQ10 found that poetry interventions were effective in alleviating symptoms of depression and post-traumatic stress disorder (PTSD) among abused adolescents (p. 71), Tegner et al. (2009) found that poetry therapy interventions improved emotional AQ11 resilience and anxiety levels in cancer patients $(n=12)$ utilizing a support center (p. 121), and Mohammadian et al. (2011) found that the use of poetry as an AQ12 intervention technique played a significant role in reducing signs of depression, anxiety, and reported stress in female undergraduate students $(n=14)$ in Iran (p. 59). Tamura (2001) further investigated whether cases of chronic schizophrenia AQ13 $(n=2)$ significantly improved after participating in one-to-one therapeutic sessions involving renku poetry and found that it indeed served a therapeutic function 
(p. 325; cf. Tamura, 1998). In other recent research, Tufford (2009) explained how AQ14Q15 engaging in practices of reading and writing poetry about the experience of infertility can help infertile individuals "synthesize and release intense emotions including loss, betrayal, frustration, and anger" (p. 1) and Kreuter (2005) also explained how the AQ16 use of poetry by prisoners in a group therapy setting "creates the possibility of insights for the prisoner, leading to change in their internal thought process and increased self-esteem," and that "By opening up an appropriate emotional channel, the prisoner regains a wider range of human expression" (p. 97). In yet another study, Ingram (2003) showed how sociocultural poetry may be used by psychothera- AQ17 pists to help oppressed group members develop their empathy skills as well as to better understand and affirm their lived experiences (p. 223) and also explained how "as an African American assistant professor at a predominantly white institution, the therapeutically metaphoric content found in poetry, specifically sociocultural poetry, has been a therapy to me personally and professionally" (p. 223). Furthermore, Furman (2005) has shown how poetry exercises can be utilized by faculty teaching AQ18 empathy to their students, presented useful exercises for teaching empathy, and discussed the poetry writing exercises of social work students to illuminate uses of poetry writing exercises for teaching (p. 103). Resultantly, since positive emotions can contribute to psychological well-being (cf. Berridge \& Kringelbach, 2011; Busseri et al., 2012; Fredrickson, 2006; Robinson \& Von Hippel, 2006; Seligman, 2010, 2011; Tang et al., 2013; Vallerand, 2012), and since several studies have indeed suggested that engaging with poetry can contribute to positive emotions (cf. Boone \& Castillo, 2008; Brillantes-Evangelista, 2013; Furman, 2005; Ingram, AQ19Q20AQ21 2003; Kreuter, 2005; Mohammadian et al., 2011; Tamura, 1998, 2001; Tegner AQ22 et al., 2009; Tufford, 2009), there are good grounds for maintaining that the practice $\mathrm{AQ}_{23 \mathrm{AQ} 24 \mathrm{Q} 25}$ of poetry can positively contribute to psychological well-being.

This section has now reviewed the recent literature on poetry and positive emotion to further clarify how practicing poetry can function as a useful means for positively influencing emotions. In order to further continue the analysis of whether practicing poetry can positively contribute to one flourishing with greater psychological well-being, the next section (Section 3) will proceed to review the recent literature on poetry and engagement (or "flow" experiences) to further clarify how poetry can function as a useful means for positively influencing engagement, and in so doing, positively influencing the second characteristic component of psychological well-being (the PERMA factor E for engagement).

\section{The practice of poetry for engagement or flow experiences}

Since psychological well-being is considered to consist of positive emotion, engagement, relationships, meaning, and accomplishment (cf. Seligman, 2010, p. $236 ; 2011$, p. 24), the second element to consider in our discussion of well-being is engagement (E). The "engaged life," Seligman (2011) proposed, "is about flow: being one with the music, time stopping, and the loss of self-consciousness during an absorbing activity" (p. 11) and Rich (2013) similarly maintained that "a good life is one characterized by complete absorption in what one does," and that "A life worth 
living then, seems to involve flow" (p. 43; cf. Nakamura \& Csikszentmihalyi, 2002, p. 89). So engagement or "flow" experience has been considered by many to constitute an important element of psychological well-being, and several recent studies have offered insight on how engagement may contribute in this way. "Flow" experience has been characterized in the literature as a "state of optimal experience that people report when they are intensely involved in doing something that is fun to do" (Csikszentmihalyi, 2000, p. 381), as "the experience of complete absorption in the present moment" (Nakamura \& Csikszentmihalyi, 2009, p. 195), and as "a state of mind characterized by focused concentration and elevated enjoyment during intrinsically interesting activities" (Strati, Shernoff, \& Kackar, 2011, p. 1050). It AQ29 has been suggested that such flow experiences characteristically occur under conditions of "perceived challenges, or opportunities for action, that stretch (neither overmatching nor underutilizing) existing skills; a sense that one is engaging challenges at a level appropriate to one's capacities," or conditions of "Clear proximal goals and immediate feedback about the progress that is being made" (Nakamura \& Csikszentmihalyi, 2002, p. 90). Further, characteristic features of flow experience have been considered to include an "Intense and focused concentration on what one is doing in the present moment," the "Merging of action and awareness," the "Loss of reflective self-consciousness (i.e., loss of awareness of oneself as a social actor)," "A sense that one can control one's actions; that is, a sense that one can in principle deal with the situation because one knows how to respond to whatever happens next," a "Distortion of temporal experience (typically, a sense that time has passed faster than normal)," and "Experience of the activity as intrinsically rewarding, such that often the end goal is just an excuse for the process" (p. 90; cf. Carli, Fave, \& Massimini, 1988; Csikszentmihalyi, 1975, 1990; Engeser, 2012, p. 3; Nakamura, 1988; Nakamura \& Csikszentmihalyi, 2002; Shernoff \& Csikszentmihalyi, 2009; Wells, 1988). In fact, Nakamura and Csikszentmihalyi (2009) proposed that "experiencing flow encourages a person to persist in and return to an activity because of the experiential rewards it premises, and thereby fosters the growth of skills over time" (p. 199) and further argued that "Because the self grows through flow experiences, we also might expect time spent in flow to predict selfesteem" (p. 199). In other recent research, Strati et al. (2011) similarly suggested that AQ30 "Flow experiences are valuable for learning and development because they provide an orientation of engagement and skill-building that carries into the future," that "Because flow states are enjoyable, they motivate individuals to continue developing skills and raising challenges to reenter flow," and consequently, that "Flow experiences thereby enhance the quality of life, add to the complexity of the developing self, and facilitate talent development in youth" (p. 1058). In "Absorption as a Therapeutic Agent," Hymer (1984) further characterized "absorption" as "the temporary loss of self through immersion in an object that eventuates in selfenhancement" (p. 93) and discussed its potentially therapeutic functions, proposing that "the patient who enters into the absorptive experience has attained a degree of separation-individuation, so that temporary, harmonious union with an object becomes a positive growth enhancing experience rather than a pathological regression" (p. 95). Thus collectively the results from these empirical and theoretical 
studies offer substantive support for the point that engagement or flow experiences constitute an important element to psychological well-being.

Importantly, since engagement or flow experience can contribute to psychological well-being, practicing poetry can contribute to psychological well-being also insofar as practicing poetry can contribute to engagement or flow experiences. And several studies have indeed suggested that engaging with poetry can contribute to engagement or flow experiences. Rathunde (2010) for instance considered interviews with distinguished lifelong learners $(n=3)$-including Pulitzer-prize winning poet Mark Strand, social scientist Donald Campbell, and medical researcher Jonas Salkto investigate whether their lifelong learning was enhanced by their capacity to become engaged or enter into a state of flow experience (p. 81). In this interview that Rathunde (2010) covers, Mark Strand reported experiencing flow while writing poetry and offered the following informative account of his experience (p. 87):

You lose your sense of time. You're completely enraptured. You're completely caught up in what you're doing [...] The idea is to be so saturated with it that there's no future or past, it's just an extended present in which you're making meaning and dismantling meaning, and remaking it, with undue regard for the words you're using. It's meaning carried to a high order. It's not just essential communication, daily communication; it's a total communication. When you're working on something and you're working well, you have feeling that there's no other way of saying what you're saying.

In another interview considered by Perry (2011) in "How a Poet Laureate Flows," AQ31 the Pulitzer Prize-winning poet Philip Levine similarly claimed to experience "flow"- or as he preferred to call it, the "fire" of inspiration-while writing poetry, offering the following informative report of his experience:

I believe the state which we call inspiration does not depend on any outside force, the muse, etc. We may feel the power of another force, but I believe the power we're feeling is the power of the presence of the total self. We feel like someone else because we are so rarely totally ourselves. (cf. Perry, 2011)

Also, in another relevant study aiming to evaluate the potentially therapeutic benefits of patients becoming absorbed in poetry and other arts, Hymer (1984) reported that "The patient who becomes absorbed [...] frequently utilizes an external object, whether a poem, music or the analyst, that blends with the imagination to rearrange his/her priorities" (p. 102) and suggested that "In such instances, boredom, anxiety or 'busy work' give way to immersion in an object that allows for the strengthening of the self through the temporary suspension of critical faculties" (p. 102) and that "Patients who become absorbed in animate and/or inanimate objects are better able to cope with a variety of problems and experience a heightened sense of well-being" (p. 93). Consequently, Hymer (1984) proposed that patients "can use absorptive experiences as means to allay anxiety by temporarily curtailing self-absorptive obsessive thinking through immersion in objects outside the self such as music, 
cinema, literature and poetry" (p. 102). Resultantly, since engagement or flow can contribute to psychological well-being (cf. Carli et al., 1988; Csikszentmihalyi, 1975, 1990, 2000; Engeser, 2012; Hymer, 1984; Nakamura, 1988; Nakamura \& Csikszentmihalyi, 2002; Rich, 2013; Seligman, 2010, 2011; Shernoff \& Csikszentmihalyi, 2009; Strati et al., 2011; Wells, 1988), and since several studies have indeed suggested that AQ33 engaging with poetry can contribute to engagement or flow (cf. Hymer, 1984; Perry, 2011; Rathunde, 2010), there are good grounds for maintaining that the practice of $\mathrm{AQ}_{3}$ poetry can positively contribute to psychological well-being.

This section has now reviewed the recent literature on poetry and engagement or flow experiences to further clarify how practicing poetry can function as a useful means for positively influencing engagement or flow experiences. In order to further continue the analysis of whether practicing poetry can positively contribute to one flourishing with greater psychological well-being, the next section (Section 4) will proceed to review the recent literature on poetry and relationships to further clarify how practicing poetry can function as a useful means for positively influencing relationships, and in so doing, positively influencing the third characteristic component of psychological well-being (the PERMA factor $\mathrm{R}$ for relationships).

\section{The practice of poetry for social relationships}

Since psychological well-being is considered to consist of positive emotion, engagement, relationships, meaning, and accomplishment (cf. Seligman, 2010, p. $236 ; 2011$, p. 24), the third element to consider in our discussion of well-being is relationships $(\mathrm{R})$. Relationships have been considered by many to constitute an important element of psychological well-being, and several recent studies have offered insight on how relationships may contribute in this way. For example, Hicks and King (2009) investigated positive affect (PA) and social relatedness as sources of information for meaning in life judgments in students $(n=150)$ and found that "individuals with strong social bonds (i.e., those low on loneliness) judged their meaning in life to be high regardless of mood induction condition," and that "Social relationships are clearly an important contributor to meaning in life" (p. 479; cf. Hicks \& King, 2007). In other relevant research, Baumeister and Leary (1995) further reviewed the empirical literature of social and personality psychology to investigate whether people need to form and maintain strong and stable social relationships, reporting from their analysis that "people form social attachments readily under most conditions and resist the dissolution of existing bonds," that "Belongingness appears to have multiple and strong effects on emotional patterns and on cognitive processes," that "Lack of attachments is linked to a variety of ill effects on health, adjustment, and well-being," and that "Existing evidence supports the hypothesis that the need to belong is a powerful, fundamental, and extremely pervasive motivation" (p. 497). Roffey (2012) has also recently argued that:

From the fundamental importance of early attachment in infancy, through learning to make friends as children and belonging to teenage groups, onto 
romantic, sexual relationships and becoming parents and workers, relationships are threaded through every stage of life and are intrinsic to many things we do

and further proposed that "Our friends may also provide the stable, positive alliance that families do not always manage" (p. 7). As Roffey (2012) persuasively argued, "Friendship is therefore critical for our psychological health" and "We often experience positive feelings in interactions with friends that boost our resilience, confidence and a positive sense of self' (pp. 7-8). In line with the results from these studies, Berridge and Kringelbach (2011) further proposed that "it might well be that in humans, at least, the social pleasures are often as pleasurable as the basic sensory pleasures" (p. 4) and Noble and McGrath (2012) have similarly suggested that "Social skills that enhance cooperation and underpin positive relationships appear to be especially important for resilience and wellbeing” (p. 21; cf. Bornstein, Davidson, Keyes, \& Moore, 2003; Cove, Eiseman, \& Popkin, 2005; National Crime Prevention, 1999; Zins, Bloodworth, Weissberg, \& Walberg, 2004). In another study investigating the association among social relationships and life satisfaction, Froh et al. (2007) reported finding that cultivating "interpersonal relationships appears to AQ35 be one way to maximize well-being" and that "therapists are advised to thoroughly assess interpersonal issues, establish treatment goals, and offer empirically supported treatments to enhance social functioning during the course of treatment" (p. 37), and in a study investigating the psychological well-being of students at school, Steinebach, Steinebach, and Brendtro (2013) similarly suggested that "peer relations can be important resources of support and opportunity for growth" and reported that a positive peer culture can positively contribute "direct effects on health and well-being, verbal skills, assertiveness, school achievement, and positive family relations" (p. 19; cf. Noble \& McGrath, 2012, p. 18; Prilleltensky \& Prilleltensky, 2006, p. 1; Steinebach, Steinebach, \& Brendtro, 2012). Thus collectively the results from these empirical and theoretical studies offer substantive support for the point that positive relationships constitute an important element to psychological well-being.

Importantly, since positive relationships can contribute to psychological wellbeing, practicing poetry can contribute to psychological well-being also insofar as practicing poetry can contribute to positive relationships. And several studies have indeed suggested that engaging with poetry can contribute to positive relationships. In "Urban Poetics," for example, Stovall (2006) investigated the opinions and practices of poetry educators $(n=4)$ and explained that the spoken word and performance poetry movement "brings people from different walks of life together to hear each other and express themselves," and that "In organizing a city-wide youth poetry slam [...] hundreds of young people convene to publicly reveal their ideas through poetry" (p. 76). Interestingly enough, in another study investigating experiential exercises designed to use poetry and visual arts in classrooms to increase the emotional intelligence of students, Morris, Urbanski, and Fuller (2005) found AQ36 that practicing poetry increased their emotional intelligence by increasing their level of awareness and emotional recognition (p. 888). As Morris et al. (2005) explained AQ37 the results from their study, "poetry can be thought of as the competency of using words and images charged with their utmost meaning," and "Because poetry and the 


\section{A. M. Croom}

fine arts have the power to shape minds and give meaning to what is seen and heard, they provide a rich contextual background for developing components of EQ [emotional intelligence]" (p. 893). In other relevant research, Abell (1998) AQ38 considered how psychotherapy sessions involving poetry therapy influenced one of his seven-year-old patients (Jason) and explained that "his poems clearly facilitated the therapist's understanding of his inner life and the development of a more empathic connection between Jason and his mother," that "Jason's poems portrayed a crucial aspect of his damaged self in a vivid manner that facilitated the empathy of others," and that "For many young children like Jason, the use of poetry can be an enriching component in their therapeutic experience" (p. 49). And in another study investigating the influence of spoken word poetry on the mood and overall well-being of poets $(n=10)$ Alvarez and Mearns (2014) reported finding that "connecting with AQ39 a community, having a forum of communication, emotional development, and having an internal drive to write and perform help the poets to feel balanced in everyday life" (p. 263). Resultantly, since positive relationships can contribute to psychological well-being (cf. Baumeister \& Leary, 1995; Berridge \& Kringelbach, 2011; Bornstein et al., 2003; Cove et al., 2005; Froh et al., 2007; Hicks \& King, AQ40 2007, 2009; National Crime Prevention, 1999; Noble \& McGrath, 2012, 2014; Prilleltensky \& Prilleltensky, 2006; Roffey, 2012; Seligman, 2010, 2011; Steinebach et al., 2012, 2013; Zins et al., 2004), and since several studies have indeed suggested that practicing poetry can contribute to positive relationships (cf. Abell, 1998; AQ41 Alvarez \& Mearns, 2014; Morris et al., 2005; Stovall, 2006), there are good grounds AQ42AQ43 for maintaining that the practice poetry can positively contribute to psychological well-being.

This section has now reviewed the recent literature on poetry and relationships to further clarify how practicing poetry can function as a useful means for positively influencing relationships. In order to further continue the analysis of whether practicing poetry can positively contribute to one flourishing with greater psychological well-being, the next section (Section 5) will proceed to review the recent literature on poetry and meaning or purpose in life to further clarify how practicing poetry can function as a useful means for positively influencing the sense of meaning or purpose in life, and in so doing, positively influencing the fourth characteristic component of psychological well-being (the PERMA factor $\mathrm{M}$ for meaning).

\section{The practice of poetry for meaning or purpose in life}

Since psychological well-being is considered to consist of positive emotion, engagement, relationships, meaning, and accomplishment (cf. Seligman, 2010, p. $236 ; 2011$, p. 24), the fourth element to consider in our discussion of well-being is meaning (M). De Muijnck (2013) for instance has recently argued that "Experiencing life as meaningful seems to be a major component of human well-being, and a major source of motivation for human action" (p. 1291) so meaning has been considered by many to constitute an important element of psychological well-being, and several recent studies have offered insight on how meaning may contribute in this way. For example, Crescioni and Baumeister (2013) explored the variety of 
needs that humans aim to fulfill in order to consider their lives meaningful and identified four major needs that included "purpose" (pp. 4-5), "values and justification" (pp. 5-6), "efficacy" (pp. 6-7), and "self-worth" (pp. 7-8). Crescioni and Baumeister (2013) further explained that "When individuals talk of finding meaning in their lives [...] they seek to interpret their own actions and experiences in terms of an existentially meaningful life story," where "Such stories depict actions and decisions as following from important, stable values and contributing to the fulfillment of one or more crucial goals" (p. 3). As Crescioni and Baumeister (2013) explain, "People's stories of their lives reveal that finding meaning in life is of crucial importance to individuals" (p. 3) and Baumeister and Newman (1994) have similarly suggested that "despite the apparent informational superiority of abstract propositions and generalizations, people seem often to prefer narratives" and that "Constructing a narrative account may be a vital first step toward understanding an event" (p. 688). As Baumeister and Newman (1994) have informatively suggested in "How Stories Make Sense of Personal Experiences":

Stories can therefore be understood as exercises in self-interpretation, by which people make sense of their experiences [...] we have proposed that the interpretive effort to make sense of personal experiences can be elaborated into four needs for meaning, which guide the construction of stories (sometimes along with interpersonal motives such as teaching, entertaining, or impressing listeners). Some stories satisfy a need for purposiveness by depicting the attainment of significant goals or fulfillment states. Others satisfy a need for justification by portraying one's actions as consistent with values, norms, and expectations and by explaining intentions in a comprehensible, acceptable fashion. Other stories help satisfy a need for efficacy by encoding useful information about how to control the environment. Lastly, many stories support the narrator's claims to self-worth by portraying him or her as a competent and attractive person. (p. 688)

In previous work, McAdams (1985) had likewise maintained that a human being's "identity" is a "life story" that "has the power to tie together past, present, and future in his or her life," "a story which is able to provide unity and purpose," and "specifies a personalized "niche" in the adult world and a sense of continuity and sameness across situations and over time" (p. 18). Indeed, McAdams (1985) argued that identities may serve many functions, but that their primary function is "integration, or the putting together of disparate parts" (pp. 57-58). In another relevant study, Wang, Lightsey, Pietruszka, Uruk, and Wells (2007) inquired into whether positive factors (including purpose in life, reasons for living, and coping styles) mediate the relationship between stressful life events and suicidal behaviors among college students $(n=416)$ and reported finding that "Both purpose in life and reasons for living had inverse effects on depression, the higher the purpose in life and reasons for living, the lower the depression, and the lower the relationship between depression and suicidal ideation/behavior," and that resultantly, "Purpose in life and reasons for living were found to be important predictors of suicide and may reduce the likelihood 


\section{A. M. Croom}

of suicidal thoughts and behaviors" (p. 202). Additionally, Bronk, Hill, Lapsley, Talib, and Finch (2009) investigated the relationship between purpose, hope, and life satisfaction among adults $(n=806)$ and reported finding that "having identified a purpose in life is associated with greater life satisfaction in adolescence, emerging adulthood, and adulthood" (p. 506) while in another study investigating religiosity as a predictor of meaning in life in a sample of women $(n=188)$, Chamberlain and Zika (1988) reported finding that "the relationship between life satisfaction and religiosity may well be mediated by meaningfulness" (p. 415). Byron and Miller-Perrin (2009) AQ44 further inquired into the relationship between faith, life purpose, and well-being in students $(n=103)$ and reported finding that "faith and life purpose contribute to the development of well-being and may be important characteristics to foster in order to enhance one's personal sense of well-being" and that "life purpose completely mediated the relationship between faith and well-being," suggesting that "the impact of faith on well-being can be explained by life purpose" (p. 68). More recently, Steger, Oishi, and Kashdan (2009) further conducted research focusing on the meaningfulness of life for participants $(n=8,756)$ across four life stages (emerging adulthood, young adulthood, middle-age adulthood, and older adulthood) and reported finding that "the more meaning in life people reported, the greater wellbeing they experienced, at all life stages" (p. 48). Thus collectively the results from these empirical and theoretical studies offer substantive support for the point that positive relationships constitute an important element to psychological well-being.

Importantly, since meaning can contribute to psychological well-being, practicing poetry can contribute to psychological well-being also insofar as practicing poetry can contribute to meaning. And several studies have indeed suggested that engaging with poetry can contribute to meaning. Jenkins (1976) for one suggested an approach to therapy that focuses on the "process of clarifying and demythologizing self-perceptions, conscious and unconscious, so that a person can move on to other representations of self and be liberated from restrictions imposed by undisclosed myths" (p. 54) and Garrett (2001) further suggested that "narratives are crucial to the phenomenon of healing: not as cure, but as a means of accepting, understanding, and minimizing suffering" (p. 187). Consistent with these results from prior research, Springer (2006) also reported in "Poetry in Therapy" that involvement in practices of $\mathrm{AQ}_{45}$ poetry and other forms of expressive writing can be productively used for "creating meaning from life experiences and making sense of one's world" as well as for "selfdiscovery and self-reflection" (p. 72) while in more recent work investigating personal meaning through the narratives of participants $(n=12)$, Bellin (2013) further reported finding that "meaning is intimately tied to a sustained sense of progress" and that "individuals can benefit from internalizing their meaning through doing, thus becoming more aware of their meaning through being" (p. 215). Resultantly, since meaning can contribute to psychological well-being (cf. Baumeister \& Newman, 1994; Bronk et al., 2009; Byron \& Miller-Perrin, 2009; AQ46 Chamberlain \& Zika, 1988; Crescioni \& Baumeister, 2013; De Muijnck, 2013; McAdams, 1985; Seligman, 2010, 2011; Steger et al., 2009; Wang et al., 2007), and since several studies have indeed suggested that practicing poetry can contribute to meaning (cf. Bellin, 2013; Garrett, 2001; Jenkins, 1976; Springer, 2006), there are AQ47 
good grounds for maintaining that the practice of poetry can positively contribute to psychological well-being.

This section has now reviewed the recent literature on poetry and meaning to further clarify how practicing poetry can function as a useful means for positively influencing meaning or purpose in life. In order to further continue the analysis of whether practicing poetry can positively contribute to one flourishing with greater psychological well-being, the next section (Section 6) will proceed to review the recent literature on poetry and personal accomplishments to further clarify how poetry can function as a useful means for positively influencing personal accomplishments, and in so doing, positively influencing the fifth characteristic component of psychological well-being (the PERMA factor A for accomplishment).

\section{The practice of poetry for accomplishment}

Since psychological well-being is considered to consist of positive emotion, engagement, relationships, meaning, and accomplishment (cf. Seligman, 2010, p. $236 ; 2011$, p. 24), the fifth element to consider in our discussion of well-being is accomplishment (A). Seligman (2010) argued that accomplishment should be considered the fifth element of positive psychology since "Many people are motivated to achieve, to have mastery, to have competence, even if it brings no positive emotion, no engagement, no relationships, and no meaning" (p. 234) and in "Achievement and the Meaningfulness of Life," James (2005) similarly maintained that, "All other things being equal, a life with some achievements in it is more meaningful than one without any achievements" (p. 429). So accomplishments have been considered by many to constitute an important element of psychological wellbeing, and several recent studies have offered insight on how accomplishments may contribute in this way. Kaplan and Maehr (1999) for one investigated the role that achievement goals play in facilitating the psychological well-being of students $(n=168)$ and reported that "Pursuing task goals was found to have a significant positive relationship with all indices of well-being, as well as with perceptions of academic efficacy and GPA" (p. 351). Hassanzadeh and Mahdinejad (2013) also investigated the relationship between happiness and achievement motivation among graduate students $(n=50)$ by having them take the Oxford Happiness Questionnaire (OHQ) and Achievement Motivation Questionnaire (AMQ) and found "a significant relationship between happiness and achievement motivation" (p. 53). In another study, Avey et al. (2011) conducted a meta-analysis that included 51 independent AQ48 samples ( $n=12,567$ employees) for the positive core construct of psychological capital (PsyCap) - which consists of "the psychological resources of hope, efficacy, resilience, and optimism" (Avey et al., 2011, p. 127) - and found that "the evidence AQ49 accumulated over the past several years supports that PsyCap, as a second-order core factor comprised of hope, optimism, efficacy, and resilience, is significantly and strongly related to employee attitudes generally considered desirable by human resource management," including “job satisfaction, organizational commitment, and psychological well-being at work," and that "PsyCap is negatively related to attitudes considered undesirable, such as employee cynicism, turnover intentions, and 


\section{A. M. Croom}

employee stress and anxiety" (p. 146). Avey et al. (2011) further reported that AQ50 “employees' PsyCap was positively related to their generally recognized desirable behaviors, such as organizational citizenship behaviors, and negatively related to their undesirable behaviors, such as deviance" (p. 146). Furthermore, in another study that investigated the level of flourishing in Chile, Sepulveda (2013) conducted a survey that measured the level of positive emotion, engagement, positive relationships, meaning, and accomplishment of a national sample of Chileans $(n=1,313)$ and found that "engagement (E), positive relationships (R), and accomplishment (A) appear more frequently among people with High Satisfaction than among those with Low Satisfaction, demonstrating a strong association of these elements with satisfaction with life" (p. 272, my emphasis). Thus collectively the results from these empirical and theoretical studies offer substantive support for the point that accomplishments constitute an important element to psychological well-being.

Importantly, since accomplishments can contribute to psychological well-being, practicing poetry can contribute to psychological well-being also insofar as practicing poetry can contribute to accomplishments. And several studies have indeed suggested that practicing poetry can contribute to accomplishments. In "The Power of Poetry," for example, Holman (1996) investigated the possible influence of a poetry therapy intervention on the treatment of a Puerto Rican teenager (George) and reported that Puerto Rican poetry "empowered" George by helping him "to move forward with his life," to work "toward establishing an integrated and positive self-identity," to "ward off the negative images held up to him by the dominant majority," and to attain "validation of his ethnic identity" (p. 380; cf. Erikson, 1966; Maldonado, 1975). As Holman (1996) further proposed, this kind of engagement with poetry may be useful in helping adolescents improve their self-esteem and respond productively to the goals of mental health treatment (p. 380; cf. Baber, 1992; Phinney, 1990). In addition, Cahnmann (2003) argued for the use of poetry as a means for educational scholarship to impact the arts, influence wider audiences, and improve teacher education, proposing that "Developing a poetic voice prepares scholars to discover and communicate findings in multidimensional, penetrating, and more accessible ways," and that scholars could fruitfully benefit from learning "how to incorporate rhythm, form, metaphor, and other poetic techniques to enhance their work" (p. 29). In "The Poetry of Achievement," Doody (2012) also AQ51 reported on the annual poetry slam hosted by the Crimson Summer Academy at Harvard University, which is a poetry program where young scholars spend three consecutive summers on the Harvard campus "amid a stimulating mix of classes, projects, field trips, and cultural activities to achieve their dream: success at college." According to the director of the Crimson Summer Academy, Maxine Rodburg, "Student success results from building a strong community, so we've built a culture in which people can get to know each other well and encourage each other." Jiovani Robles, a Crimson Summer Academy graduate and emcee of the annual poetry slam, also reported that "CSA is a program that really pushes you [...] It allows students to really think about what they want to do for the future and helps them think for themselves. And by bringing them onto the Harvard campus, it exposes them to college life" (cf. Doody, 2012). In a study that reviewed the recent emergence of AQ52 
poetry as a legitimate form of creative arts therapy, Kempler (2003) also proposed AQ53 that poetry therapy could be used to help patients accomplish the development of an authentic personal voice (pp. 217-219) and to progress "from pain and confusion to self-understanding and clear, honest expression" (p. 220). And in other relevant research, Jordan and L'Abate (1995) found that the use of poetry therapy in a group AQ54 setting facilitated self-acceptance and self-actualization in patients (p. 225), Springer (2006) found that poetry therapy benefited trauma survivors and clients in AQ55 successfully recovering from addiction to alcohol and other drugs (p. 69), and Meunier (2003) investigated the use of poetry writing in short-term therapy for a AQ56 patient with schizophrenia $(n=1)$ and reported finding that poetry therapy could be used "to address mature emotional issues (anger and mortality) in a productive and enlightening way" (p. 236). Resultantly, since accomplishment can contribute to psychological well-being (cf. Avey et al., 2011; Hassanzadeh \& Mahdinejad, 2013; AQ57 James, 2005; Kaplan \& Maehr, 1999; Seligman, 2010, 2011; Sepulveda, 2013), and since several studies have indeed suggested that practicing poetry can contribute to accomplishment (cf. Baber, 1992; Cahnmann, 2003; Doody, 2012; Erikson, 1966; Holman, 1996; Jordan \& L'Abate, 1995; Kempler, 2003; Maldonado, 1975; AQ58AQ59 Meunier, 2003; Phinney, 1990; Springer, 2006), there are good grounds for AQ60AQ61AQ62 maintaining that the practice of poetry can positively contribute to psychological well-being.

This section has now reviewed the recent literature on poetry and personal accomplishments to further clarify how poetry can function as a useful means for positively influencing personal accomplishments. Therefore, throughout the course of our discussion we have reviewed substantial evidence supporting the main claim advanced in this article that practicing poetry can positively contribute to one flourishing with greater psychological well-being by positively influencing their emotions (cf. Section 2), engagement (cf. Section 3), relationships (cf. Section 4), meaning (cf. Section 5), and accomplishment (cf. Section 6). That is to say, in order to determine whether engaging in poetry practice can positively contribute to one flourishing with greater psychological well-being, Section 2 reviewed the recent literature on poetry and positive emotion in order to explain how poetry can function as a useful means for positively influencing the emotions, and in so doing, positively influencing the first characteristic component of psychological well-being (the PERMA factor $\mathrm{P}$ for positive emotion), Section 3 reviewed the recent literature on poetry and engagement in order to explain how poetry can function as a useful means for positively influencing engagement, and in so doing, positively influencing the second characteristic component of psychological well-being (the PERMA factor $\mathrm{E}$ for engagement), Section 4 reviewed the recent literature on poetry and relationships in order to explain how poetry can function as a useful means for positively influencing relationships, and in so doing, positively influencing the third characteristic component of psychological well-being (the PERMA factor R for relationships), Section 5 reviewed the recent literature on poetry and meaning in order to explain how poetry can function as a useful means for positively influencing meaning, and in so doing, positively influencing the fourth characteristic component of psychological well-being (the PERMA factor $M$ for meaning), and Section 6 reviewed the recent 


\section{A. M. Croom}

literature on poetry and accomplishment in order to explain how poetry can function as a useful means for positively influencing accomplishments, and in so doing, positively influencing the fifth characteristic component of psychological well-being (the PERMA factor A for accomplishments). Consequently, Sections 2-6 of this article have demonstrated that practicing poetry can positively influence all five of the PERMA factors of psychological well-being (cf. Seligman, 2010, 2011), and that as a result, there are empirically supported grounds for the main claim argued for here that the practice of poetry can positively contribute to one flourishing with greater psychological well-being.

\section{Conclusion}

In "Flourish," the psychologist Martin Seligman (2010) proposed that psychological well-being consists of "PERMA: positive emotion, engagement, relationships, meaning, and accomplishment" (p. 236; cf. Seligman, 2011, p. 24). Although the question of what constitutes flourishing or psychological well-being has been long debated among scholars (cf. Aristotle, 2011; McMahon, 2006; Peterson \& Seligman, 2004), the recent literature has suggested that a paradigmatic or prototypical case of psychological well-being would manifest most or all of the aforementioned PERMA factors of positive emotion, engagement, relationships, meaning, and accomplishment. The recent literature on the practice of poetry has also suggested that poetry practice may be utilized as "an effective therapeutic tool" for patients suffering from a variety of ailments (cf. Kempler, 2003, p. 217; cf. Ingram, 2003) so it seemed AQ63AQ64 plausible that practicing poetry could positively contribute to one flourishing with greater psychological well-being. However, recent studies on the practice of poetry had not yet been reviewed and integrated under the PERMA framework from positive psychology to further explore and explicate this possibility. In order to further explore and explicate the possibility that poetry can be used to contribute to flourishing with greater psychological well-being, Section 1 ("Introduction") began by introducing the PERMA model of psychological well-being proposed by Seligman (2010) — which considered well-being as consisting of positive emotions, engagement, relationships, meaning, and accomplishment-and proposed that it offers a promising conceptual framework to apply in understanding findings from the recent literature on the practice of poetry and the psychology of well-being. We then reviewed recent research from poetry therapy and the psychology of well-being to investigate whether practicing poetry could plausibly be used to increase positive emotions, engagement or flow experiences, interpersonal relationships, meaning or purpose in life, and personal accomplishments. Specifically, Section 2 ("The Practice of Poetry for Positive Emotion") drew upon the empirical and theoretical literature to argue that poetry can be used to positively influence emotions, Section 3 ("The Practice of Poetry for Engagement or Flow Experiences") drew upon the empirical and theoretical literature to argue that poetry can be used to positively influence engagement or flow experiences, Section 4 ("The Practice of Poetry for Relationships") drew upon the empirical and theoretical literature to argue that poetry can be used to positively influence social relationships, Section 5 ("The Practice of Poetry 
for Meaning or Purpose in Life") drew upon the empirical and theoretical literature to argue that poetry can positively influence the experience of meaning or purpose in life, and Section 6 ("The Practice of Poetry for Accomplishment") drew upon the empirical and theoretical literature to argue that poetry can be used to positively contribute to one's accomplishments. In this way, the present article contributes to the extant literature on poetry therapy and psychological well-being by showing how practicing poetry can positively influence all five of the PERMA factors, and consequently, that there are empirically supported grounds for the claim argued here that practicing poetry can positively contribute to one flourishing with greater psychological well-being. In short, I have argued here that the practice of reading, writing, and reciting poetry with others on a regular basis is not a merely passive and ineffective activity, but rather an active and productively effective one that typically involves engaging a variety of different intrapersonal cognitive-emotional components (such as those involving memory, sensorimotor tasks, and positive effect) as well as interpersonal social partners (such as the authors one reads or listens to, the partners one writes or recites with, and the audience one reads or recites for), and that practicing poetry is therefore a truly productive activity that is fully capable of positively influencing both our personal and social lives.

\section{Acknowledgments}

My warm thanks go out to Nick Mazza and the anonymous reviewers of fournal of Poetry Therapy for their kindness and support regarding the publication of this article.

\section{References}

Aristotle. (2011). Nicomachean ethics. Chicago: University of Chicago Press.

Baber, C. (1992). Ethnic identity development and literacy education. Reading Psychology, 13(1), 91-98. doi:10.1080/027027192130107

Baumeister, R. F., \& Leary, M. R. (1995). The need to belong: Desire for interpersonal attachments as a fundamental human motivation. Psychological Bulletin, 117, 497-529. doi:10.1037/0033-2909.117. 3.497

Baumeister, R. F., \& Newman, L. S. (1994). How stories make sense of personal experiences: Motives that shape autobiographical narratives. Personality and Social Psychology Bulletin, 20, 676-690. doi: $10.1177 / 0146167294206006$

Bellin, Z. (2013). Meaning through being: Reclaiming the wholeness of personal meaning. fournal of Humanistic Counseling, 52, 208-222. doi:10.1002/j.2161-1939.2013.00043.x

Berridge, K. C., \& Kringelbach, M. L. (2011). Building a neuroscience of pleasure and well-being. Psychology of Well-Being, 1(1), 3. doi:10.1371/journal.pcbi.1000437

Bornstein, M. H., Davidson, L., Keyes, C. L. M., \& Moore, K. A. (2003). Well-being: Positive development across the life course. Mahwah: Lawrence Erlbaum.

Bronk, K. C., Hill, P. L., Lapsley, D. K., Talib, T. L., \& Finch, H. (2009). Purpose, hope, and life satisfaction in three age groups. The fournal of Positive Psychology, 4, 500-510. doi:10.1080/ 17439760903271439

Busseri, M. A., Choma, B. L., \& Sadava, S. W. (2012). Subjective temporal trajectories for subjective well-being. The fournal of Positive Psychology, 7(1), 1-15. doi:10.1080/17439760.2011.565784

Cahnmann, M. (2003). The craft, practice, and possibility of poetry in educational research. Educational Researcher, 32(3), 29-36. doi:10.3102/0013189X032003029

Carli, M., Fave, A. D., \& Massimini, F. (1988). The quality of experience in the flow channels: Comparison of Italian and U.S. students. In M. Csikszentmihalyi \& I. Csikszentmihalyi (Eds.), 


\section{A. M. Croom}

Optimal experience: Psychological studies of flow in consciousness (pp. 288-306). Cambridge: Cambridge University Press.

Chamberlain, K., \& Zika, S. (1988). Religiosity, life meaning and wellbeing: Some relationships in a sample of women. Fournal for the Scientific Study of Religion, 27, 411-420. doi:10.2307/1387379

Cove, E., Eiseman, M., \& Popkin, S. J. (2005). Resilient children: Literature review and evidence from the HOPE VI panel study. Washington: The Urban Institute.

Crescioni, A. W., \& Baumeister, R. (2013). The four needs for meaning, the value gap, and how (and whether) society can fill the void. In J. A. Hicks \& C. Routledge (Eds.), The experience of meaning in life: Classical perspectives, emerging themes, and controversies (pp. 3-15). Dordrecht: Springer.

Croom, A. M. (2012). Music, neuroscience, and the psychology of well-being: A précis. Frontiers in Psychology, 2, 393. doi:10.3389/fpsyg.2011.00393

Croom, A. M. (2014). Embodying martial arts for mental health: Cultivating psychological well-being with martial arts practice. Archives of Budo Science of Martial Arts and Extreme Sports, 10, 53-64.

Csikszentmihalyi, M. (1975). Beyond boredom and anxiety: Experiencing flow in work and play. San Francisco, CA: Jossey-Bass.

Csikszentmihalyi, M. (1990). Flow: The psychology of optimal experience. New York, NY: Harper and Row.

Csikszentmihalyi, M. (2000). Flow. In A. E. Kazdin (Ed.), Encyclopedia of psychology, Volume 3 (pp. 381382). Oxford: Oxford University Press.

De Muijnck, W. (2013). The meaning of lives and the meaning of things. Fournal of Happiness Studies, 14, 1291-1307. doi:10.1007/s10902-012-9382-y

Engeser, S. (2012). Advances in flow research. Dordrecht: Springer.

Erikson, E. H. (1966). The concept of identity in race relations: Notes and queries. Daedalus, 95, $145-171$.

Fredrickson, B. L. (2006). Unpacking positive emotions: Investigating the seeds of human flourishing. The Fournal of Positive Psychology, 1(2), 57-59. doi:10.1080/17439760500510981

Garrett, C. (2001). Weal and woe: Suffering, sociology, and the emotions of Julian of Norwich. Pastoral Psychology, 49, 187-203. doi:10.1023/A:1004886311430

Hassanzadeh, R., \& Mahdinejad, G. (2013). Relationship between happiness and achievement motivation: A case of university students. Fournal of Elementary Education, 23, 53-65.

Hicks, J. A., \& King, L. A. (2007). Meaning in life and seeing the big picture: Positive affect and global focus. Cognition and Emotion, 21, 1577-1584. doi:10.1080/02699930701347304

Hicks, J. A., \& King, L. A. (2009). Positive mood and social relatedness as information about meaning in life. The fournal of Positive Psychology, 4, 471-482. doi:10.1080/17439760903271108

Holman, W. D. (1996). The power of poetry: Validating ethnic identity through a bibiotherapeutic intervention with a Puerto Rican adolescent. Child and Adolescent Social Work fournal, 13, 371-383. doi: $10.1007 / \mathrm{BF} 01875855$

Hymer, S. (1984). Absorption as a therapeutic agent. Fournal of Contemporary Psychotherapy, 14(2), 93-108. doi:10.1007/BF00946308

James, L. (2005). Achievement and the meaningfulness of life. Philosophical Papers, 34, 429-442. doi:10.1080/05568640509485166

Jenkins, G. P. (1976). Pastoral psychotherapy and the symbolic. Pastoral Psychology, 25(1), 54-67. doi:10.1007/BF01761147

Kaplan, A., \& Maehr, M. L. (1999). Achievement goals and student well-being. Contemporary Educational Psychology, 24, 330-358. doi:10.1006/ceps.1999.0993

Maldonado, D. (1975). Ethnic self-identity and self-understanding. Social Casework, 56, 618-622.

Manning, P. K. (1999). High risk narratives: Textual adventures. Qualitative Sociology, 22, 285-299. AQ65 doi:10.1023/A:1022003520356

McAdams, D. P. (1985). Identity and the life story. In D. P. McAdams (Ed.), Power, intimacy, and the life story: Personological inquiries into identity (pp. 31-68). New York, NY: Guilford Press.

McMahon, D. M. (2006). Happiness: A history. New York, NY: Atlantic Monthly Press.

Miller, D. K. (1978). Poetry therapy with psychotic patients. Fournal of Contemporary Psychotherapy, 9(2), 135-138. doi:10.1007/BF01815982 
Nakamura, J. (1988). Optimal experience and the uses of talent. In M. Csikszentmihalyi \& I. Csikszentmihalyi (Eds.), Optimal experience: Psychological studies of flow in consciousness (pp. 319-326). Cambridge: Cambridge University Press.

Nakamura, J., \& Csikszentmihalyi, M. (2002). The concept of flow. In C. R. Snyder \& S. J. Lopez (Eds.), Handbook of positive psychology (pp. 89-105). Oxford: Oxford University Press.

Nakamura, J., \& Csikszentmihalyi, M. (2009). Flow theory and research. In S. Lopez \& C. R. Snyder (Eds.), Oxford handbook of positive psychology (pp. 195-206). Oxford: Oxford University Press.

National Crime Prevention. (1999). Pathways to prevention: Developmental and early intervention approaches to crime in Australia. Canberra: National Crime Prevention Attorney-General's Department.

Noble, T., \& McGrath, H. (2012). Wellbeing and resilience in young people and the role of positive relationships. In S. Roffey (Ed.), Positive relationships: Evidence based practice across the world (pp. 1734). Dordrecht: Springer.

Noble, T., \& McGrath, H. (2014). Well-being and resilience in school settings. In G. A. Fava \& C. Ruini (Eds.), Increasing psychological well-being in clinical and educational settings: Interventions and cultural contexts (pp. 135-152). Dordrecht: Springer.

Peterson, C., \& Seligman, M. E. P. (2004). Character strengths and virtues: A handbook and classification. Oxford: Oxford University Press.

Phinney, J. S. (1990). Ethnic identity in adolescents and adults. Psychological Bulletin, 108,499-514. doi:10.1037/0033-2909.108.3.499

Prilleltensky, I., \& Prilleltensky, O. (2006). Promoting well-being: Linking personal, organizational, and community change. Hoboken: Wiley.

Rashid, T., Anjum, A., Chu, R., Stevanovski, S., Zanjani, A., \& Lennox, C. (2014). Strength based resilience: Integrating risk and resources towards holistic well-being. In G. A. Fava \& C. Ruini (Eds.), Increasing psychological well-being in clinical and educational settings: Interventions and cultural contexts (pp. 153-176). Dordrecht: Springer.

Rathunde, K. (2010). Experiential wisdom and optimal experience: Interviews with three distinguished lifelong learners. Fournal of Adult Development, 17(2), 81-93. doi:10.1007/s10804-009-9083-x

Rich, G. J. (2013). Finding flow: The history and future of a positive psychology concept. In J. D. Sinnott (Eds.), Positive psychology: Advances in understanding adult motivation (pp. 43-60). Dordrecht: Springer.

Robinson, M. D., \& Von Hippel, W. (2006). Rose-colored priming effects: Life satisfaction and affective priming. The fournal of Positive Psychology, 1, 187-197. doi:10.1080/17439760600885705

Roffey, S. (2012). Introduction to positive relationships: Evidence-based practice across the world. In S. Roffey (Ed.), Positive relationships: Evidence based practice across the world (pp. 1-16). Dordrecht: Springer.

Seligman, M. E. P. (2010). Flourish: Positive psychology and positive interventions. The tanner lectures on human values, 7 October. Michigan: University of Michigan.

Seligman, M. E. P. (2011). Flourish: A visionary new understanding of happiness and well-being. New York, NY: Free Press.

Seligman, M. E. P., Ernst, R. M., Gillham, J., Reivich, K., \& Linkins, M. (2009). Positive education: Positive psychology and classroom interventions. Oxford Review of Education, 35, 293-311. doi:10.1080/03054980902934563

Sepulveda, C. I. (2013). Flourishing in Chile: How to increase well-being in the country? Estudos Contemporaneos Da Subjetividade, 3, 267-275.

Shernoff, D., \& Csikszentmihalyi, M. (2009). Flow in schools: Cultivating engaged learners and optimal learning environments. In R. Gilman, E. S. Heubner, \& M. J. Furlong (Eds.), Handbook of positive psychology in schools (pp. 131-145). New York, NY: Routledge.

Slavin, S. J., Schindler, D., Chibnall, J. T., Fendell, G., \& Shoss, M. (2012). PERMA: A model for institutional leadership and culture change. Academic Medicine, 87, 1481. doi:10.1097/ ACM.0b013e31826c525a 


\section{A. M. Croom}

Steger, M. F., Oishi, S., \& Kashdan, T. B. (2009). Meaning in life across the life span: Levels and correlates of meaning in life from emerging adulthood to older adulthood. The fournal of Positive Psychology, 4, 43-52. doi:10.1080/17439760802303127

Steinebach, C., Steinebach, U., \& Brendtro, L. K. (2012). Peer-beziehungen und Gesundheit im AQ66 Jugendalter. In C. Steinebach, D. Jungo, \& R. Zihlmann (Eds.), Positive Psychologie in der Praxis: Anwendung in Psychotherapie, Beratung und Coaching (pp. 153-161). Weinheim: Beltz.

Steinebach, C., Steinebach, U., \& Brendtro, L. K. (2013). Positive youth psychology: Lessons from positive peer culture. Reclaiming Children and Youth, 21, 15-21.

Stovall, D. (2006). Urban poetics: Poetry, social justice and critical pedagogy in education. The Urban Review, 38(1), 63-80. doi:10.1007/s11256-006-0027-5

Tang, D., Kelley, N. J., Hicks, J. A., \& Harmon-Jones, E. (2013). Emotions and meaning in life: A motivational perspective. In J. A. Hicks \& C. Routledge (Eds.), The experience of meaning in life: Classical perspectives, emerging themes, and controversies (pp. 117-128). Dordrecht: Springer.

Vallerand, R. J. (2012). The role of passion in sustainable psychological well-being. Psychology of WellBeing, 2(1), 1. doi:10.1111/j.1745-6924.2008.00085.x

Wang, M. C., Lightsey, O. R., Pietruszka, T., Uruk, A. C., \& Wells, A. G. (2007). Purpose in life and reasons for living as mediators of the relationship between stress, coping, and suicidal behavior. The Fournal of Positive Psychology, 2, 195-204. doi:10.1080/17439760701228920

Wells, A. J. (1988). Self-esteem and optimal experience. In M. Csikszentmihalyi \& I. Csikszentmihalyi (Eds.), Optimal experience: Psychological studies of flow in consciousness (pp. 327-341). Cambridge: Cambridge University Press.

Zins, J. E., Bloodworth, M. R., Weissberg, R. P., \& Walberg, H. J. (2004). The scientific base linking social and emotional learning to school success. In J. E. Zins, R. P. Weissberg, M. C. Wang, \& H. J. Walberg (Eds.), Building academic success on social and emotional learning: What does the research say? (pp. 2-22). New York, NY: Teacher College Press. 